\title{
Functional Group Positions and Contact Behavior in Problem-Solving Groups
}

\author{
Thomas Bachmann ${ }^{1,2}$ (D) \\ Accepted: 3 November 2021 / Published online: 21 January 2022 \\ (c) The Author(s) 2022
}

\begin{abstract}
This article in the journal Gruppe. Interaktion. Organization (GIO) deals with the application of the theory of functional psycho-dynamic positions by Raoul Schindler on problem-solving groups. Until now, there has been no empirical research substantiating this model and the emergence of the group positions. To do so, the relationship between the functional group positions and members' contact behavior was examined with a sociometrical approach. A study with 138 participants from 22 groups was conducted. The results clearly confirm the model and show typical contact behavior patterns for each group position. Finally, types of informal group structures were compared in regards to group performance and practical applications for agile teams and shared leadership.
\end{abstract}

Keywords Group dynamics - Group positions · Group roles $\cdot$ Contact behavior $\cdot$ Sociometrics $\cdot$ Agile teams $\cdot$ Shared leadership

\section{Functional Group Positions and Contact Behavior in Problem-Solving Groups}

Due to the recent development of new work and agile organizations a renaissance of teamwork and group dynamics can be observed in science and practice (Bachmann 2019a; Königswieser et al. 2013; Kozlowski and Bell 2003; Rapp et al. 2016; Schermuly 2019). Agile teams i.e. scrum teams (Rising and Janoff 2000), such as circles in holacratic organizations (Robertson 2015), are based on an individual's self-organization within often continually changing team constellations (Mathieu et al. 2019). As a result of these ongoing underlying group development processes (Tuckman 1965; Wheelan 2009), group members have to constantly negotiate their positions within the informal structure of the group. Each individual needs to find and define their role by negotiating directly or non-directly with the other members (Schindler 1957). Conflicts may arise during these processes, potentially creating a negative dynamic, especially when there is a lack of conflict management competen-

\footnotetext{
Dipl.-Psych., PD Dr. rer. nat Thomas Bachmann

thomas.bachmann@hu-berlin.de

Department of Psychology, Humboldt University, 10099 Berlin, Germany

2 artop Institute at Humboldt University, Berlin, Germany
}

cies within the group members, poor process moderation, no support from competent leaders or (agile-)coaches, or when the group is embedded in fuzzy or insufficient organizational structures or processes (Janz et al. 1997). The concept of shared leadership is often propagated in this context (Carson et al. 2007; D'Innocenzo et al. 2016; Moe et al. 2009). In contrast to distributed leadership (Barry 1991), shared leadership is a more informal and dynamic process. Shared leadership "originates with individual members of a team engaging in activities that influence the team and other team members in areas related to direction, motivation and support" (Carson et al. 2007, pp. 1218-1219). Moe et al. (2009, p. 3) wrote: "Leadership is rotated to the person with the key knowledge, skills, and abilities for the particular issues facing the team at any given moment". In the following article we will apply an innovative interdisciplinary approach, which is both theoretical and empirical, to bridge the gap between the ideas of shared leadership and a work team's underlying group dynamics.

Group dynamics now looks back on a tradition that has lasted more than 70 years. The ideas, experiments, and theories of Kurt Lewin (1890-1947), which he developed at MIT in his Research Center of Group Dynamics (Lewin 1945), are the most well-known in this field. Those seen as the "fathers" of group dynamics include Jacob Levi Moreno (1889-1974), the inventor of psychodrama and sociometry (Moreno 2012), as well as the Austrian, Raoul Schindler 


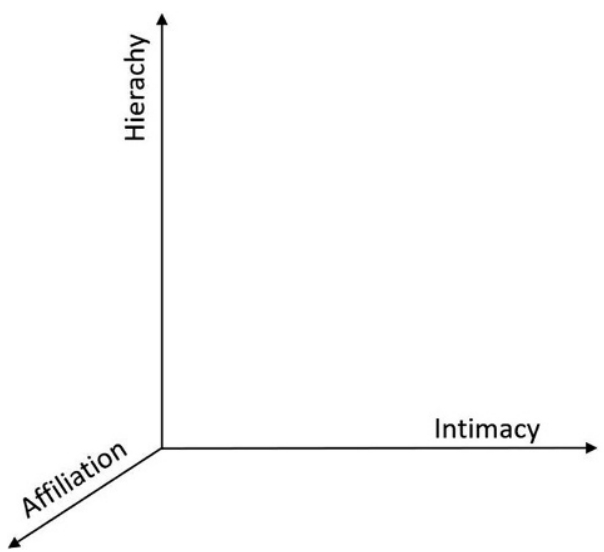

Fig. 1 The group dynamic space-GDS (Amann 2009; Yalom 1995)

(1923-2014), with his psycho-dynamic rank position model for groups (Schindler 1957).

\section{The group dynamic space}

A first deep immersion into the inner processes of a group can be made through the group dynamic space model (GDS; Amann 2009; Yalom 1995). GDS describes three fundamental dimensions along which groups typically develop conflicts over the course of their development. The conflict dimensions are hierarchy (i.e. power), affiliation, and intimacy. Yalom (1995, pp. 302) describes them as "top or bottom", "in or out", and "near or far" conflicts. The model postulates that all group dynamic conflicts can be assigned to at least one of these three dimensions. So far, there is no empirical evidence for this model. It is mainly used in the context of practical group dynamic trainings (Fig. 1).

The hierarchy dimension describes the phenomenon whereby members of a group move from what was until then a symmetric non-hierarchical position among the others into an asymmetric hierarchical position, through initiatives, ideas, or suggestions. Here the crucial questions are: Who will prevail? What is being done? Who is being followed? Who leads and represents the group? Who has influence on the group? Who will shape the common standards and values? And as a result: Who has a higher status than other group members? Groups are, with regard to this dimension, extremely sensitive to permanent asymmetrization and attempt to re-symmetrize after a certain time (Königswieser et al. 2013). The group members permit asymmetrization for as long as they think it is useful for the group. Conflicts in groups in regards to which direction to take, goals, approaches, evaluation of a particular matter etc., are therefore often an expression of an inner process of hierarchy and power formation in which it needs to be decided who (at least for a time) gets to say how the group

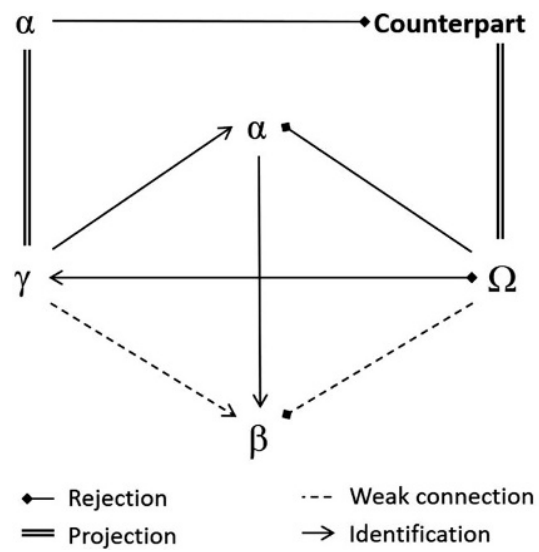

Fig. 2 The functional psycho-dynamic group position (FPGP)-Model adapted from Schindler (1957)

will proceed and who is to follow. The concept of shared leadership in the context of new work is very close to this group dynamic dimension, since leadership occurs in the group whenever there is someone who has the best ideas or competencies for a given problem or situation (Carson et al. 2007; D'Innocenzo et al. 2016; Moe et al. 2009).

The second dimension refers to alignment. In this case, conflicts occur when the system boundaries are not clearly defined. Who belongs and who does not? Who is committed, and with which goals? Is everyone going to be involved, or are some just along for the ride? Who is also a member of other rival groups? Many teams in organizations have to deal with conflicts in this dimension. Particularly in of modern organizations and highly varied structures, it is not always clear who belongs where, especially when individuals are a part of multiple teams. However, if a group is to act properly, a clear system boundary represented by a common understanding and team goals is important for the development of internal qualities such as closeness, a sense of commitment, contact, cohesion, and ultimately, common values. If this is not the case, team members feel irritated by each other, which negatively impacts their relationships and feelings of affiliation.

The third dimension is called intimacy. Conflicts on this dimension occur primarily around the regulation of closeness and distance between group members. Examples of questions asked for this dimension are: Is everyone's personal involvement in the group process equally intense? Is everyone opening up appropriately to the group's purpose-particularly with regard to the sharing of feelings? Have all group members built up an equally strong feeling of closeness with each other? Differences, such as when two group members are close to each other but keep their distance from the other members, unavoidably leads to tension within the group, since an additional relationship context is immediately presumed. The result of appropriate intimacy is trust or psychological safety (Edmondson and Lei 2014; 
Meyer et al. 2018; Schein and Bennis 1965), which means that the group members feel safe enough to take personal risk by voicing different opinions or points of view.

\section{The Schindler-Model}

When one continues along this line of thought, the GDSModel assumes an internal hierarchy which emerges in the group through interaction processes. Schindler's model (Schindler 1957) of functional psycho-dynamic group positions (FPGP-Model) becomes helpful at this point. He assumes that in order to fulfill a task or to fend off a threat, a group needs to internally develop a functional structure which makes it possible for goals to be pursued, actions to arise, and for as many group members as possible to have the same understanding of the task (which Schindler calls the "other party" or "the counterpart" (in German: "Das Gegenüber"). Within this structure group members occupy certain positions. The term position is important as it signifies that a person can leave it, like a position on a playing field. Hence, what is being spoken of here are not the roles, nor the personality types described by this model, but instead the functions which characterize a group internally (Fig. 2).

The first and the highest hierarchical functional position is Alpha. The person who assumes this position, or is assigned this position, takes over the task of leading the group towards a goal and of managing the handling of the other party. In doing so, Alpha acts in an externally oriented manner and depends on the group members who follow and support him or her. In addition, Alpha defines the image of the other party. The group sees the other party equally through Alpha, i.e. the reality construct of the group system is heavily influenced by the alpha position. The other members trust Alpha and accept his or her strong influence on group decisions.

The beta position is occupied by the expert who assists and supports Alpha. He or she is more internally focused on the group than Alpha. As a result, there is often an ambivalent relationship between the two; Alpha needs Beta in order to lead, and Beta needs Alpha in order to partake in the power (to lead), however his or her influence on group decisions is non-directive.

The actual work is done by the group members in the gamma positions who identify with Alpha and share the Alpha's view of the other party. The Gammas have no specific role patterns, they cooperate to get the work done, each of them with his or her own competencies and capabilities.

The fourth and particularly interesting position is that of the Omega. Here it is important not to confuse it with the term used in biology, in which omega describes the individual with the lowest rank (Schjelderup-Ebbe 1922). Rather,
Omega is the position opposite Alpha, which therefore has a significantly different view of the other party, the task, or the goal. The gamma positions experience this as a threat, as it disrupts their identification with Alpha. Simultaneously, Omega is also seen as a threat by Alpha and Beta, as he or she calls their leadership position into question. Thus, Omega is often stigmatized as a disruptive factor or a toxic team member and an attempt is often made to exclude him or her. This is because, in the words of Luhmann (1985), this person disrupts the established communication patterns through re-entry, which means they say what is not allowed to be said in the group. The behavior of the omega position and how the group deals with them is indicative of the reflexive capabilities of a group with regard to reaching its goal, of how it handles varying points of view, of its cohesiveness, and of how power is concentrated within in the group. Hence, Omega is to be seen as corrective of Alpha, and simultaneously an indicator for the state of the overall system (Schindler 1957). In systemic family therapy, such positions are called the "index patient" or the "symptom owner" (von Schlippe und Schweitzer 2013). The efficacy and development of a group depends significantly on how constructively the conflict between Alpha and Omega is handled. Should Omega become too strong, Alpha runs the risk of losing their position; should Alpha become too strong, there is no longer a corrective position in the group, and there is a threat of stagnation (Schindler 1957). At this point it is useful to differentiate the omega position into two types: the active and the passive omega position. Opposite to the active omega position, the passive omega is characterized by an outside or outcast behavior induced by the other group members. In both cases the omega positions are associated with irritation by the other group members, the active omega has influence, and the passive does not.

This functional model of group positions should not be taken for a model of group or team roles-even when there are some superficial similarities. Most of the well-known models refer to work teams and have a more formal character which results from a team's professional goal and task orientation Ancona and Caldwell (1992), Bales (1950), Barry (1991), Belbin (1993), Benne and Sheats, (1948), DuBrin (1995), McCann and Margerison (1995), Parker (1996) or Mumford et al. (2008). For a detailed overview see Caughlin (2010). "The term role is a set of expectations which group members share concerning the behavior of a person ..." (Hare 1976, p. 131). The positions in Schindler's model emerge situationally, depending on the counterpart of the group which results from informal processes, and represent essential system functions. Therefore, it is a dynamic process model. They must be seen as more general and fundamental, comparable to the AGIL-Scheme 
Fig. 3 Forms of contact

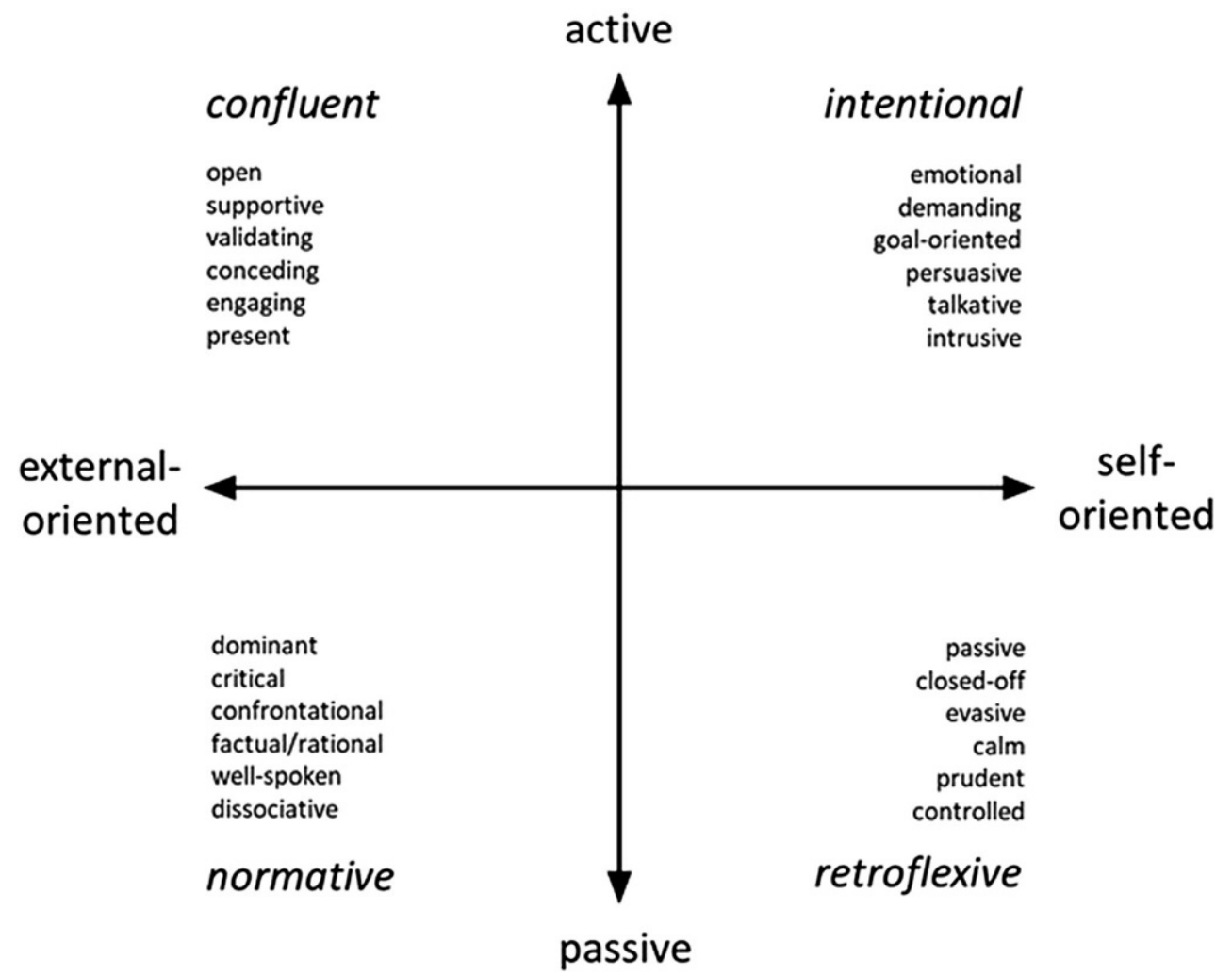

functions outlined by Parsons (1961), and they must emerge if a group is to take action (Bachmann 2017).

In the context of agile work, it is crucial for leaders and coaches to analyze the team members' positions to better understand conflicts and other patterns by asking: (1) Who holds the informal alpha position? (2) What is the other party? Me, the team leader, or the threat which has triggered the current process of change in the team? (3) Who shares which views with whom in the team? Who supports Alpha? (4) How can I improve collaboration with Alpha, and in doing so obtain better access to the team? (5) Which issues does the omega position address? (6) Are there perhaps unclear structures, unresolved task sections or goal conflicts being addressed here which I, as a person in a leadership position, would need to deal with? These and many other practical questions can be addressed and answered with the FPGP-Model by Schindler (1957).

\section{Forms of contact}

The prediction of behavior (B) by personality traits is a long runner in psychology from the early beginning up to now. Therefore, recent research focusses more on the interaction of person (P) and situation $(\mathrm{S}), B=f(P, S)$ as Lewin (1951) already pointed out (see for example Fleeson 2001, 2007; Rauthmann 2012, 2013; Ziegler 2014; Ziegler et al. 2014).
Regarding informal roles in groups, no or only small correlations could be found (for example Stewart et al. 2005; Caughlin 2010). Furthermore, Mathieu et al. (2019) showed in a review of meta-analyses that the Big Five personality traits (Costa and McCrae 1985) had only a small influence, if any, on team effectiveness.

For this reason, we choose an entirely different approach with origins in Gestalt therapy (Perls et al. 1951). We postulate that the informal functional structure of a group is a result of the group members' interactions and these interactions are mostly characterized by the communication style, and how it is perceived by the other members of the group. From a Gestalt therapy perspective, an individual's interaction with others is characterized by their contact behavior (Bachmann 2019b, 2021; Perls et al. 1962; Wheeler 1998). There are four main forms of behavior which occur during the contact process. It is their function to control and to regulate the contact process of the self with its environment, for example, in conversations with others, in relationships, within a group, a team, or a family. The forms can be arranged within a system of two coordinating dimensions: active_passive and self-orientated-externallyoriented (Fig. 3). As a result of the contact process, the novelty, e.g. something to eat, feel, hear, learn, understand, etc. will either be assimilated and become a part of the self, or it will be rejected. The whole process is driven by the individuals' needs which can be defined as poor states on 
a biological, psychical, or social system level e.g. hunger, affection, or affiliation. The goal of the contact process is it to compensate for these poor states and to fulfill needs in a given moment.

The four contact styles are confluency, projection, retroflection, and egotism. To take a step away from connotations bound to psychotherapy, we suggest naming them more neutrally - the confluent, the intentional, the retroflexive, and the normative form of contact (Bachmann 2019, 2021).

The main function of the confluent form of contact is to adapt the self to the environment, (i.e. to the other members of the group). The needs of the self are rejected, and in their place the others' requests are regarded and adopted. This form allows for weak contact only since the individual's needs are being neglected. The confluent form has a positive image within social contexts because it is characterized by positive emotions, confirmation and support of others, approachability, and open mindedness (Bachmann 2019). Furthermore, it helps in building connections with others. This form of contact corresponds to the system function adaption in Talcott Parsons AGIL-Model (Parsons 1961).

The function of the intentional form of contact is to generate and attain goals by making projections of the desired state of need fulfillment. When people are acting in this form they are focused, energetic, and single-minded, but are also found to be assuming or encroaching to others. This contact form, like the three others too, has positive and negative aspects e.g. it can cause irritation in the social context. The intentional form corresponds to the system function goal attainment in the AGIL-Model (Parsons 1961).

The retroflexive form's function is to inhibit impulses and affects. In this mode, people act shy and modest, suppress negative emotions like anger and fury, but also positive emotions like joy and pleasure. The typical behavior is nonacting, and to such a degree that the acting impulses stay inside the self and absorb psychic energy. This form of contact corresponds to the system function integration in the AGIL-Model (Parsons 1961). This contact form also only allows for weak contact and may cause irritation in social relationships.

The normative form protects the self from uncontrolled changes through the assimilation of the novelty. In this mode people take control in a social interaction by setting the norm of what is right or wrong. They act factually and impersonally, criticize, and evaluate others, and behave from a distant position. It is also typical for the normative form to show coolness and not to show surprise. This contact form is typical in contexts where people must protect themselves from being publicly hurt by others. It corresponds to the system function latent structure maintenance in the AGIL-Model (Parsons 1961). The normative form can evoke trust but also irritation, depending on the way the person is using his or her influence or power in a given social situation.

At the beginning of Gestalt therapy, the contact styles were understood as contact interruptions, because from a more radical point of view, they prevent real contact. A recent perspective understands them as functions for regulating contact in a given situation (Wheeler 2013), depending on the context, the others, the needs, the personality, and the social expectations (Bachmann 2019, Bachmann 2022).

\section{Purpose of the present study}

The goal of the following study is to investigate the relationship between the FPGP-Model (Schindler 1957) and the group members' forms of contact (Bachmann 2019) in problem-solving groups to gain more insights how an informal structure in a group occurs and how this structure influences the groups problem solving performance. Therefore, an approach must be found for identifying the individuals' informal positions. For this purpose, sociometric analysis (Hale 2009; Moreno 2012) will be used based on the dimensions of the GDS: hierarchy, affiliation, and intimacy (Amann 2009; Yalom 1995). According to this, the study may find answers to the following questions:

1. Is there empirical evidence for the existence of the group positions assumed by the FPGP-Model, and are all of these positions verifiable in every group?

2. Do the individuals in each of the positions show a typical contact style?

3. Is there a correlation between problem-solving performance and the patterns of the FPGP's?

The theoretical framework allows for the following hypotheses to be tested in an empirical study with problem solving groups.

1. There are four main types of informal group positions which can be clearly distinguished along the dimensions of the GDS.

1.1. The alpha position is characterized by high scores on influence and trust, and low scores on irritation.

1.2. The beta position is characterized by high scores on trust, but low scores on influence and irritation.

1.3. The gamma position is characterized by low or medium scores on the three dimensions. There is no distinct pattern.

1.4. The omega position can be divided into two subfunctions namely active omega and passive omega. 
Table 1 Descriptive Statistics and Intercorrelations for GDS-variables

\begin{tabular}{lllllll}
\hline Variables & $n$ & $M$ & $S D$ & 1 & 2 & - \\
\hline 1. Influence & 139 & 0.51 & 0.33 & - & - & - \\
2. Trust & 139 & 0.51 & 0.26 & 0.11 & - \\
3. Irritation & 139 & 0.49 & 0.49 & $0.26^{* *}$ & $-0.54^{* *}$ \\
\hline
\end{tabular}

$* p<0.05, * * p<0.01$

Table 2 Cluster Means and Standard derivations of the GDS-variables, and ANOVA results

\begin{tabular}{|c|c|c|c|c|c|c|c|c|c|c|c|c|c|}
\hline \multirow[t]{2}{*}{ Variable } & \multicolumn{10}{|c|}{ Clusters } & \multicolumn{3}{|l|}{ ANOVA } \\
\hline & $\bar{M}$ & $S D$ & $M$ & $S D$ & $M$ & $S D$ & $M$ & $S D$ & $M$ & $S D$ & $\overline{F \text { ratio }}$ & $D f$ & $\eta^{2}$ \\
\hline Cluster & 2 & & 1 & & - & - & - & - & - & - & - & - & - \\
\hline Influence & 0.37 & 0.30 & 0.56 & 0.33 & - & - & - & - & - & - & $10.02 * *$ & 1136 & 0.07 \\
\hline Trust & 0.78 & 0.17 & 0.39 & 0.30 & - & - & - & - & - & - & $117.84 * *$ & 1136 & 0.46 \\
\hline Irritation & 0.22 & 0.19 & 0.61 & 0.22 & - & - & - & - & - & - & $97.69 * *$ & 1136 & 0.42 \\
\hline Cluster & 2 & & 1.1 & & 1.2 & & - & - & - & - & - & - & - \\
\hline Influence & 0.37 & 0.30 & 0.36 & 0.22 & 0.93 & 0.09 & - & - & - & - & $83.11 * *$ & 2135 & 0.55 \\
\hline Trust & 0.78 & 0.17 & 0.34 & 0.19 & 0.47 & 0.20 & - & - & - & - & $67.43 * *$ & 2135 & 0.50 \\
\hline Irritation & 0.22 & 0.19 & 0.58 & 0.21 & 0.65 & 0.23 & - & - & - & - & $50.39 * *$ & 2135 & 0.43 \\
\hline Cluster & 2.1 & & 2.2 & & 1.1 & & 1.2 & & - & - & - & - & - \\
\hline Influence & 0.12 & 0.14 & 0.64 & 0.15 & 0.36 & 0.22 & 0.93 & 0.09 & - & - & $122.50 * *$ & 3134 & 0.73 \\
\hline Trust & 0.84 & 0.11 & 0.73 & 0.20 & 0.34 & 0.19 & 0.47 & 0.47 & - & - & $46.87 * *$ & 3134 & 0.51 \\
\hline Irritation & 0.20 & 0.21 & 0.24 & 0.24 & 0.58 & 0.21 & 0.65 & 0.65 & - & - & $33.58 * *$ & 3134 & 0.43 \\
\hline Cluster & 2.1 & & 2.2 & & 1.2 & & 1.1.1 & & 1.1.2 & & - & - & - \\
\hline Influence & 0.12 & 0.14 & 0.64 & 0.15 & 0.93 & 0.09 & 0.15 & 0.10 & 0.49 & 0.17 & $173.89 * *$ & 4133 & 0.84 \\
\hline Trust & 0.84 & 0.12 & 0.73 & 0.20 & 0.47 & 0.20 & 0.39 & 0.17 & 0.31 & 0.31 & $36.15 * *$ & 4133 & 0.52 \\
\hline Irritation & 0.20 & 0.21 & 0.24 & 0.16 & 0.65 & 0.23 & 0.43 & 0.15 & 0.68 & 0.18 & $36.25 * *$ & 4133 & 0.52 \\
\hline
\end{tabular}

The order of the clusters in the table corresponds with the dendrogram in Fig. 4

$* p<0.05, * * p<0.01$

1.4.1. The active omega position is characterized by high scores on influence and irritation, but low scores on trust.

1.4.2. The passive omega position is characterized by high scores in irritation, and low scores on influence and trust.

2. There are typical relationships between the group positions and the individual contact style.

2.1. Confluent and intentional forms are typical for the alpha position.

2.2. Confluent and retroflexive forms are typical for the beta position.

2.3. The confluent form is typical for the gamma positions.

2.4. Intentional and normative forms are typical for the active omega position.

2.5. The retroflexive form is typical for the passive omega position.

3. Groups in earlier stages of development, when not all positions are occupied, are more flexible, agile, and more divers in opinions which leads to better results in complex group tasks.
Not all of the hypotheses can be derived from the implications of the theoretical models, but rather from many years of empirical observations in which the author of this article surveyed groups in self lead training courses. The survey instruments are described in the following section.

\section{Method}

\subsection{Sample}

The data collection was realized in a T-Group setting (Lewin 1945) within an additional occupational coach training program. The mean age of the 147 participants was 40.14 years, $70.10 \%$ were female and $29.90 \%$ male. All participants had graduated from college or university. The mean group size was 6.84 with a range from 4 to 9 . There were a total of 22 groups.

\subsection{Design}

The groups started the first day of training with two sessions of $90 \mathrm{~min}$ each. In the first session the group's task was to 
Fig. 4 Hierarchical cluster analysis of the sociogram data (Ward-Method)

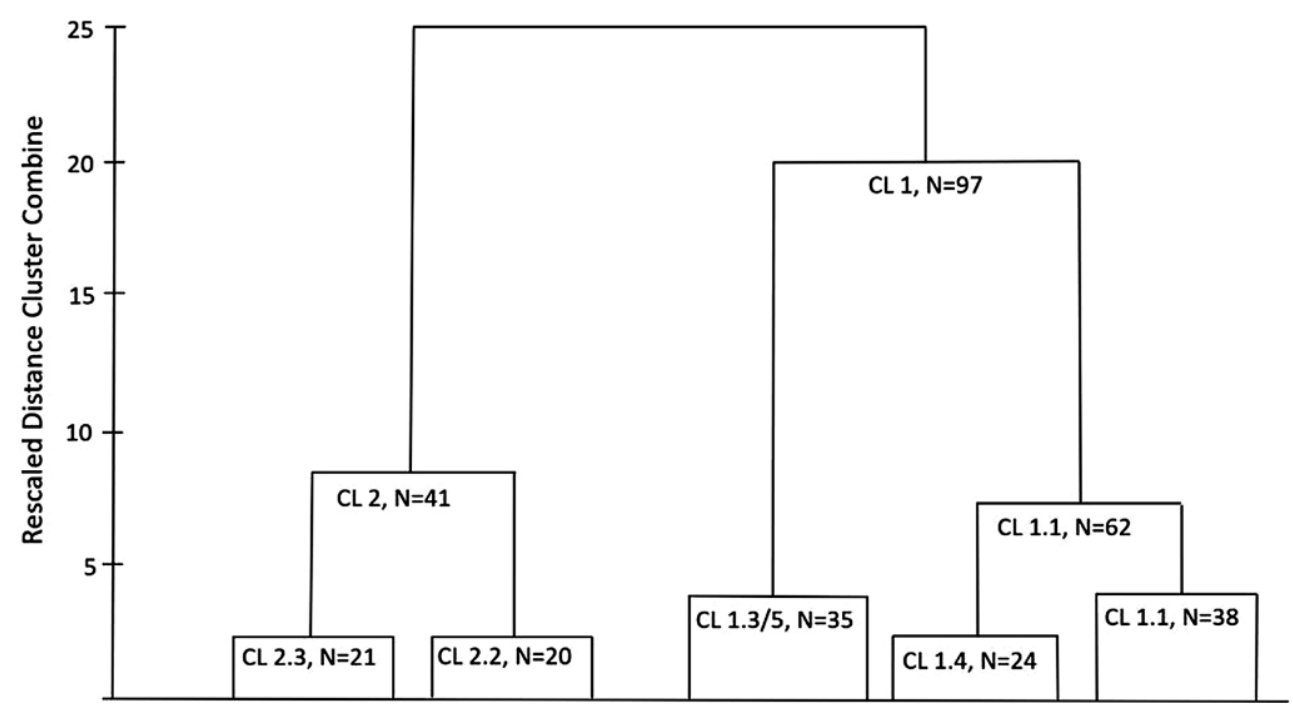

get familiar with each other and to warm up for the second session where they had to solve the following classic group cooperation task: After a plane crash in the desert, rank 15 unharmed objects, from most to least important, which would give the group a maximum chance of survival. The group's solution could then be compared with an expert solution based on rank differences. These differences can be used as indicators for the group's performance.

\subsection{Instruments}

After three more 60-minute sessions the next day, in which they reflected on the group process, a sociometric analyses was conducted by the trainer in each group. The group reflection consisted of a task in which each group member was to select a card, from nine colored cards, which best described each group member. They were given $5 \mathrm{~min}$ to prepare and then were asked to give the cards to the respective group members. There were three red cards for the dimension influence ("you are someone who has influence on the group decisions"), three green cards for trust ("you are someone I trust in this group"), and three yellow cards for irritation ("you are someone who irritates me sometimes, e.g. someone who it is not easy for me to understand or relate to"). They were instructed to give all 9 cards to the others, but not more than one from the same color to the same person. For the data analysis, the number of cards for each dimension were used, corrected by the maximum number of cards an individual could get in his or her group. As a result, a coefficient for each dimension was computed with values between 0 and 1 .

The contact functions were measured by self and external assessment during training. To do so a standardized questionnaire developed in a former study (Bachmann 2019b) was used. The items and scale parameters can be seen in the
Appendix. There were four experienced trainers who conducted the program. They were instructed by the author to perform the external assessment. Due to numerous restrictions on time, didactical structure, and the methodology of the coach training program, each individual was only rated by one trainer. For that reason, no inter-rater correlation could be calculated, a disadvantage of this study which was conducted in an applied, not a primary, research context. For the data analyses IBM SPSS Statistics 22 was used. The $\alpha$-level was set to $5 \%$.

\section{Results}

\subsection{FPGP-Model}

The relationships between the three dimensions of the GDS were investigated by correlation analysis. The coefficients show a small positive correlation between influence and irritation and a strong negative correlation between trust and irritation. There is no significant correlation between trust and influence (Table 1).

In the next step, a hierarchical cluster analysis with the dimensions of the GDS was conducted using the WardMethod with the goal of determining the number of clusters in the data. The distance matrix was computed by using the squared Euclidian distance. As shown in Fig. 4, there were two main clusters with two second order clusters each. The scores for the dimensions of the GDS for the cluster solutions are shown in Table 2. Already a first significant result of this analysis can be pointed out; namely, the dimension of intimacy, represented by the question on trust, which out of the main clusters has the greatest difference in scores between Cluster $1(N=97)$ and Cluster $2(N=41)$. The dimension irritation shows a smaller effect, the effect 


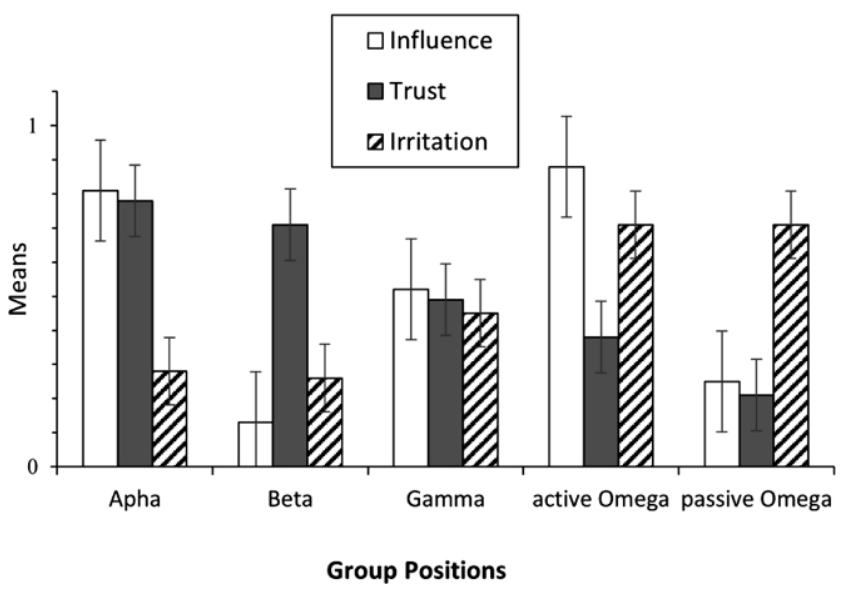

Fig. 5 Final cluster centers after 6 iterations with the sociogram data of the GDS. Note. Error bars show standard errors

of influence is also significant but small. On next level, the dimension of power has the most impact, represented by the question on influence. This leads to a split of Cluster 1 into Cluster $1.1(N=62)$ and Cluster 1.2 $(N=35)$. In the next step Cluster 2 is split into Cluster $2.1(N=21)$ and Cluster 2.2 $(N=20)$ also by the impact of the influence dimension. The same happens on the last level where Cluster 1.1 split into Cluster 1.1.1 $(N=24)$ into Cluster 1.1.2 $(N=38)$ (Fig. 4).

Regarding Schindler's model in the Four-Cluster-Solution, Cluster 2 can be interpreted as the alpha position and Cluster 3 as the beta position. Both score high on the dimension of trust and low on irritation, whereas Alpha also scores high on the dimension of influence. Cluster 4 can be seen as the omega position because of high values on influence and irritation and lower scores on trust. Cluster 1 represents the gamma position with mostly medium scores.

An additional Five-Cluster-Solution is shown in Table 2. On this level, the gamma-cluster (Cluster 1) is split into Cluster 1.1 and 1.4 which can be interpreted as the passive omega position. This cluster is characterized by low influence and medium trust and irritation. The results of the Ward-cluster analysis support hypotheses 1 to 1.4.

In the next step a k-means cluster analysis was performed. Thereby, the patterns of the five clusters from the Ward-solution were used as initial cluster centers. According to the hypotheses on the patterns of group positions on the three dimensions, the initial values were transformed into bipolar scales from 0 to 1 with a center point of 0.5. The initial cluster centers for the three dimensions influence, trust, and irritation were $\alpha(1,1,0), \beta(0,1,0)$, $\gamma(0.5,0.5,0.5), \Omega_{\text {active }}(1,0,1)$, and $\Omega_{\text {passive }}(0,0,1)$. The results are shown in Fig. 5.

Table 3 shows the ANOVA results of the quick cluster procedure. The data show that the largest differences in mean values between clusters exist on the dimension influence. The dimensions trust and irritation differentiate the clusters much less, but the results are similar to the hierarchical cluster analysis. The difference between the two cluster methods is that the k-means cluster show clearer and more concise characterization of the group types. In sum, the results support the hypotheses 1 to 1.4.

Table 3 Cluster means and standard derivation of the sociogram data and ANOVA results

\begin{tabular}{|c|c|c|c|c|c|c|c|c|c|c|c|c|c|}
\hline \multirow{3}{*}{ Variable } & \multirow{2}{*}{\multicolumn{2}{|c|}{$\frac{\alpha}{N=17}$}} & \multicolumn{2}{|l|}{$\underline{\beta}$} & \multicolumn{2}{|l|}{$\gamma$} & \multicolumn{2}{|c|}{$\Omega_{\text {active }}$} & \multicolumn{2}{|c|}{$\Omega_{\text {passive }}$} & \multicolumn{3}{|l|}{ ANOVA } \\
\hline & & & \multicolumn{2}{|c|}{$N=34$} & \multicolumn{2}{|c|}{$N=29$} & \multicolumn{2}{|c|}{$N=36$} & \multicolumn{2}{|c|}{$N=22$} & \multirow[b]{2}{*}{$F$ ratio } & \multirow[b]{2}{*}{$D f$} & \multirow[b]{2}{*}{$\eta^{2}$} \\
\hline & $\bar{M}$ & $S D$ & $M$ & $S D$ & $M$ & $S D$ & $\bar{M}$ & $S D$ & $M$ & $S D$ & & & \\
\hline \multirow{2}{*}{$\begin{array}{l}\text { Influence } \\
\text { Trust }\end{array}$} & 0.81 & 0.19 & 0.13 & 0.13 & 0.52 & 0.10 & 0.88 & 0.13 & 0.25 & 0.16 & $167.13 * *$ & 4133 & 0.83 \\
\hline & 0.78 & 0.78 & 0.71 & 0.22 & 0.49 & 0.14 & 0.38 & 0.20 & 0.21 & 0.14 & $39.11 * *$ & 4133 & 0.54 \\
\hline Irritation & 0.28 & 0.28 & 0.26 & 0.20 & 0.45 & 0.15 & 0.71 & 0.20 & 0.73 & 0.18 & $37.13 * *$ & 4133 & 0.53 \\
\hline
\end{tabular}

$* p<0.05, * * p<0.01$

Table 4 K-means cluster centers (z-values) and standard derivation of the contact forms and ANOVA results

\begin{tabular}{|c|c|c|c|c|c|c|c|c|c|c|c|c|c|}
\hline \multirow[t]{3}{*}{ Variable } & \multirow{2}{*}{\multicolumn{2}{|c|}{$\frac{\alpha}{N=16}$}} & \multirow{2}{*}{\multicolumn{2}{|c|}{$\frac{\beta}{N=28}$}} & \multirow{2}{*}{\multicolumn{2}{|c|}{$\frac{\gamma}{N=21}$}} & \multirow{2}{*}{\multicolumn{2}{|c|}{$\frac{\Omega_{\text {active }}}{N=29}$}} & \multirow{2}{*}{\multicolumn{2}{|c|}{$\frac{\Omega_{\text {passive }}}{N=18}$}} & \multicolumn{3}{|c|}{ ANOVA } \\
\hline & & & & & & & & & & & \multirow[b]{2}{*}{$F$ ratio } & \multirow[b]{2}{*}{$D f$} & \multirow[b]{2}{*}{$\eta^{2}$} \\
\hline & $\bar{M}$ & $S D$ & $M$ & $S D$ & $M$ & $S D$ & $M$ & $S D$ & $M$ & $S D$ & & & \\
\hline Confluent & 0.22 & 0.73 & 0.02 & 0.73 & 0.27 & 0.80 & -0.22 & 0.95 & -0.25 & 0.80 & 1.81 & $\begin{array}{l}4,107 \\
111\end{array}$ & 0.06 \\
\hline Intentional & 0.27 & 0.46 & -0.21 & 0.67 & -0.19 & 0.65 & 0.34 & 0.77 .85 & -0.31 & 0.74 & $4.38 * *$ & $\begin{array}{l}4,107 \\
111\end{array}$ & 0.14 \\
\hline Retroflexive & -0.45 & 0.50 & ,40 & 0.80 & $\begin{array}{l}-0.05 \\
-0.25\end{array}$ & 0.86 & -0.32 & 0.83 & 0.44 & 0.62 & $6.05 * *$ & $\begin{array}{l}4,107, \\
111\end{array}$ & 0.18 \\
\hline Normative & -0.10 & 0.74 & -0.35 & 0.71 & - & 0.56 & 0.41 & - & 0.14 & 0.57 & $5.06 * *$ & $\begin{array}{l}4,107, \\
111\end{array}$ & 0.16 \\
\hline
\end{tabular}

$* p<0.05, * * p<0.01$ 


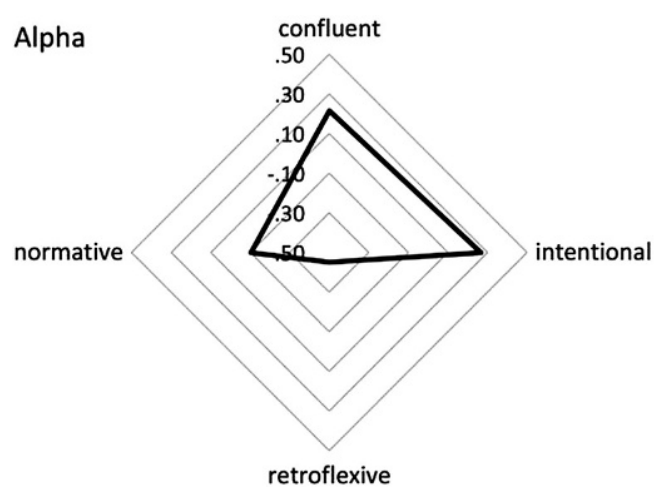

Fig. 6 Alpha position and forms of contact means (z-values)

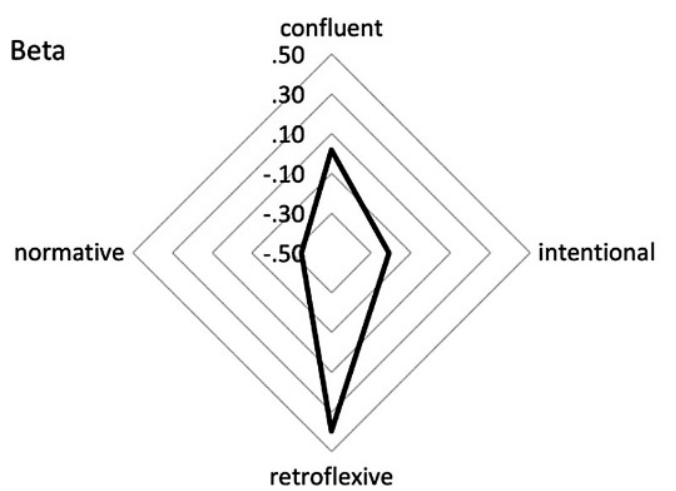

Fig. 7 Beta position and forms of contact means (z-values)

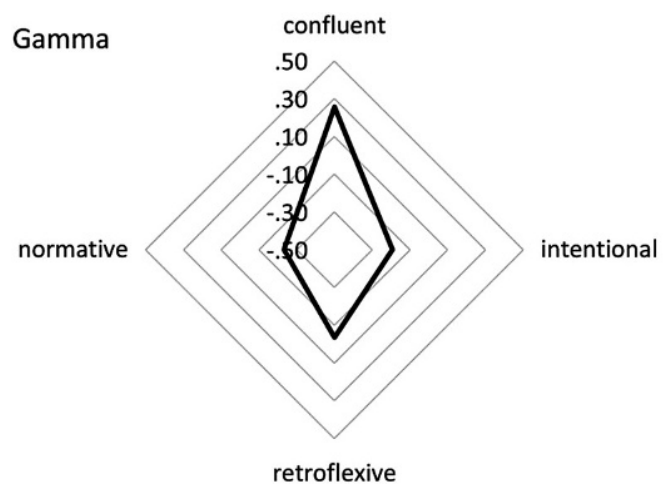

Fig. 8 Gamma position and forms of contact means (z-values)

\subsection{Contact forms}

In this section the relationship between contact forms and group position were analyzed. The ANOVA shows significant differences for the intentional, retroflexive and normative contact forms. For the confluent contact form, no significant differences in means between the group position could be detected (Table 4).

The spider charts in Fig. 6, 7, 8, 9 und 10 concisely depicts the individuals' contact forms in relation to the different group positions. The alpha position is characterized by the confluent and the intentional form but not by the

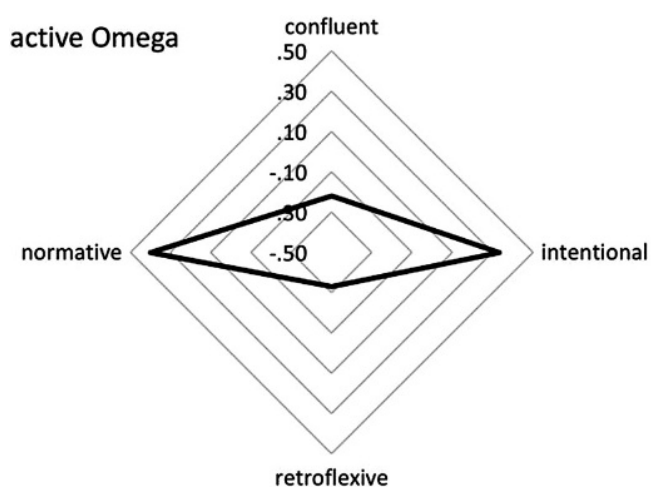

Fig. 9 Active omega position and forms of contact means (z-values)

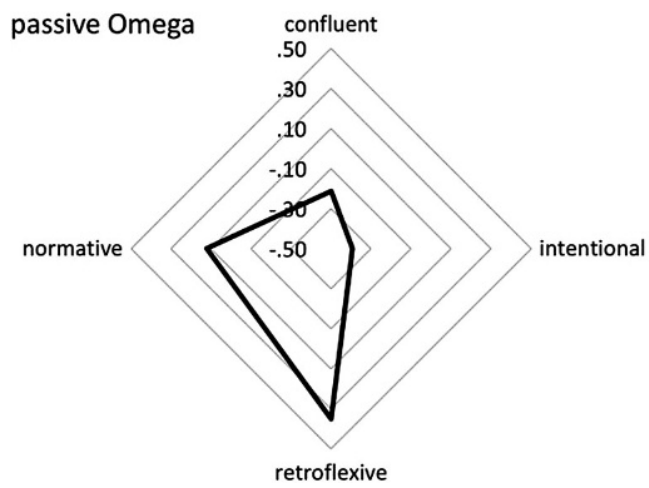

Fig. 10 Passive omega position and forms of contact means (z-values)

retroflexive and the normative form. Individuals in the Beta position show strong retroflexive behavior and a slight confluent behavior. The gamma position is marked by confluent behavior and a low value on the other contact forms. Active Omega differs entirely from the other positions. It is characterized by strong intentional and normative behavior and low values in terms of the confluent and the retroflexive forms. The passive Omega position shows high values for the retroflexive and medium values for the normative form, whereby the confluent and the intentional form show low values. These results essentially support hypotheses 2 to 2.5 .

\subsection{Problem solving performance}

In order to thoroughly answer research question 1 , the groups were analyzed with regard to the frequency of the group positions. Table 5 shows the cast of the group positions for each group. The results show that not all of the group positions are equally filled. There are only a few groups which are close to a model conform cast. This means that every primary position is occupied by only one individual (e.g. groups 12 to 15 ). The general pattern is that if the alpha position is occupied than there are fewer Betas and active Omegas and more passive Omegas and vice versa. 
Table 5 Number of individuals on the group positions for each group

\begin{tabular}{llllll}
\hline Group Number & \multicolumn{5}{l}{ Group positions } \\
\cline { 2 - 6 } & $\alpha$ & $\beta$ & $\gamma$ & $\Omega_{\text {active }}$ & $\Omega_{\text {passive }}$ \\
\hline 1 & 0 & 1 & 1 & 2 & 0 \\
2 & 0 & 1 & 1 & 2 & 1 \\
3 & 0 & 1 & 2 & 2 & 1 \\
4 & 0 & 1 & 2 & 2 & 2 \\
5 & 0 & 2 & 1 & 3 & 1 \\
6 & 0 & 2 & 3 & 1 & 0 \\
7 & 0 & 2 & 4 & 0 & 2 \\
8 & 0 & 3 & 1 & 3 & 0 \\
9 & 0 & 3 & 1 & 3 & 0 \\
10 & 0 & 3 & 3 & 2 & 0 \\
11 & 0 & 4 & 0 & 3 & 0 \\
12 & 1 & 1 & 0 & 2 & 1 \\
13 & 1 & 1 & 1 & 2 & 1 \\
14 & 1 & 1 & 1 & 2 & 2 \\
15 & 1 & 1 & 2 & 1 & 2 \\
16 & 1 & 2 & 2 & 2 & 0 \\
17 & 2 & 0 & 1 & 1 & 1 \\
18 & 2 & 2 & 1 & 1 & 1 \\
19 & 2 & 2 & 1 & 2 & 2 \\
20 & 3 & 0 & 1 & 0 & 2 \\
21 & 3 & 1 & 0 & 0 & 3 \\
\hline & & & & &
\end{tabular}

If there is no Alpha than there are more Betas and active Omegas. An obvious interpretation of these results would be that the two clusters of groups are at different stages of development. Some groups are still in the storming phase (according to Tuckman 1965), whereas in others, all positions have already been occupied and have thus developed an informal structure and are subsequently in the norming or performing phase.

In the last step of data analysis, the groups were split by the median of the performance indicator. To compare the groups' solutions with the experts' solution, the sums of the 15 ranked differences were calculated. A perfect fit would be indicated by the value 0 , the greatest difference by the value 112 . Because of missing data, only 17 groups could be investigated in this analysis. The mean of the rank differences in the upper half was $M=44.42(S D=4.70)$, whereas the mean of the lower half was $M=58.13(S D=4.89)$. Table 6 shows the number of individuals in each group position by median-split.
The results in Table 6 show different tendencies in the distribution of functional group positions. In the groups with better results (upper half), fewer alpha positions were occupied, more beta and active omega, and fewer passive omega. In the groups in the lower half, more alpha positions were occupied, fewer beta and active omega, and more passive omega positions. This leads to the assumption that groups are more successful in the cooperative and complex task used here before they have formed a stable informal structure. For a good task solution, it seems to be more important that there are differing opinions, ideas, conflicts and contradictions in the group (Alpha-Omega conflict), but also several persons who ensure trust and cohesion in the group (Beta) and altogether fewer passive members (passive Omega). Due to the small sample size, these results are unfortunately not significant $\left(X^{2} \mathrm{df}=6.82 ; p=0.14\right)$ but can be included in the discussion of results as an obvious trend.

\section{Discussion}

In the presented study, four theoretical approaches from group and interaction research were examined and related to each other: the FPGP-Model by Schindler (1957), the GDS (Amann 2009; Yalom 1995), and forms of contact (Bachmann 2019) based on a sociometric analysis (Moreno 2012). The aim was to obtain empirical evidence of Schindler's model and to describe, on the one hand, how group members are perceived in their positions by the group, and on the other hand, which contact behavior is typical for the respective functional position in the group.

The results can be seen as strong evidence for the Schindler-Model (1957). Despite the popularity of the model, especially in German speaking countries, the author is not aware of any empirical studies on it. This may be due to the difficult operationalization of the group positions and the superficial similarity to models from behavioral biology (e.g. Schjelderup-Ebbe 1922).

The group positions found in this study by the cluster analyses deviate in part from Schindler's descriptions. Especially the beta position, which is described by Schindler as an expert position, but here it mainly presents itself as a position of trust. The fifth position, passive omega, is not mentioned by Schindler at all. According to the results

Table 6 Number of individuals on the group positions for each group median-split by performance

\begin{tabular}{|c|c|c|c|c|c|c|}
\hline \multirow[t]{2}{*}{ Median-split groups } & \multicolumn{6}{|c|}{ Group positions } \\
\hline & $\alpha$ & $\beta$ & $\gamma$ & $\Omega_{\text {active }}$ & $\Omega_{\text {passive }}$ & $\Sigma$ \\
\hline Upper half (8 groups) & 6 & 17 & 11 & 19 & 6 & 59 \\
\hline Lower half ( 9 groups) & 10 & 11 & 10 & 10 & 12 & 53 \\
\hline Sum & 16 & 28 & 21 & 19 & 18 & 112 \\
\hline
\end{tabular}


of the present study, it can be understood as an outsider position. The most important aspect of Schindler's model is that he considers the group positions functionally. It is about an internal differentiation of the group that emerges in the course of group development depending on the counterpart, so that the group can act in a coordinated manner and achieve goals. The model should therefore not be confused with typologies, personality, or evolution biology models.

The behavior of the group members that comes to light in the process of building an informal structure within the group can be described by different and typical forms of contact (Bachmann 2019b, 2021). According to this, shared leadership is not limited to a single person, e.g. those in the alpha position, but is rather the result of interaction processes characterized by mutual trust, empowerment, and support, but also by differentiation and conflict. The results of this study lead to a revisited FPGP-Model.

Depending on the counterpart of the group and the developmental stage, five typical functional positions in small problem-solving groups can occur:

1. The alpha position, the leader, is characterized by forms of contact which induce goal orientation for the group (intentional form of contact) and connection the group members' needs (confluent form of contact). The main qualities of this position are influence and trust.

2. The beta position, the confidant, is characterized by the forms of contact which induce connection to the needs of the group members (confluent form of contact) and restraint (retroflexive form of contact). The main quality of this position is trust.

3. The gamma position, the group member, is characterized by the form of contact which induces connection to the needs of the other group members (confluent form of contact). There is no especially pronounced quality of this position.

4. The active omega position, the opposer, is characterized by forms of contact which induce goal orientation for the group (intentional form of contact) and strong opinions and evaluations (normative form of contact). The main qualities of this position are influence and a lack of affiliation, both of which are indicated by group members' irritation.

5. The passive omega position, the outsider, is characterized by the form of contact which is marked by restraint (the retroflexive form of contact). The main quality of this position is a lack of affiliation, which is expressed through group members' irritation.

The results of this study have led to new and distinctive views on informal group positions. First and foremost, the GDS-Dimension illustrates the group members' perception of the positions and the forms of contact their behavior in the interaction process. The model could therefore be ap- plied to team analysis and leadership training. For example, in the context of shared leadership, the revised SchindlerModel can help to explain why, where, and how leadership occurs in a group during a collaborative process in response to the task the group is facing. The first important result of the study is the role of trust on the informal structuring of the group. The dimension on trust is polarized between two subgroups represented by Alpha and Omega. The extent to which a dynamic stability can develop from trust and competition is crucial for the development and performance of groups, without it a group would not be able to act and make decisions. Further research on group dynamics and informal group structures could certainly identify even more factors that promote the development of trust and psychological safety in groups. Besides context factors, formal leadership, task dependency and other important aspects from team effectiveness research (Mathieu et al. 2019), the interactions on a micro level represented by the forms of contact can lead to deeper insights on these inner processes.

The second interesting result relates to group performance and informal structures. We conclude that groups perform better on complex problem-solving tasks before an informal structure has stabilized. Once a structure has emerged, its success depends on whether the group has identified the appropriate Alpha or not. These results correspond to a study by Bachmann (2019a) were three types of problem-solving groups were identified: (1) groups without the alpha position (no final informal structure); (2) groups with a final structure and the appropriate Alpha, which achieve good results; and (3) groups with a final structure and an ill-suited Alpha, which achieve only poor results. This supports the shared leadership concept and clearly demonstrates the importance of keeping teams agile and flexible, especially since it is difficult to evaluate when the best informal structure has emerged.

\section{Limitations}

This study is subject to some limitations due to the practical investigative context, which was not primarily research oriented. This led to restrictions on the study design, the composition of participants, and the survey instruments. One crucial point is the data quality. Although the data were from different sources (self-assessment, external assessment, peer assessment on individuals, external performance measure) and of different levels (rating and metric data) no real observation data could be obtained. Further investigations should take this in account.

On the other hand, this is also a benefit, as the ecological validity of the results originate from real life adults in an extra occupational training context and not from psychol- 
ogy students who must participate in several studies to meet the requirements of their studies.

Open Access This article is licensed under a Creative Commons Attribution 4.0 International License, which permits use, sharing, adaptation, distribution and reproduction in any medium or format, as long as you give appropriate credit to the original author(s) and the source, provide a link to the Creative Commons licence, and indicate if changes were made. The images or other third party material in this article are included in the article's Creative Commons licence, unless indicated otherwise in a credit line to the material. If material is not included in the article's Creative Commons licence and your intended use is not permitted by statutory regulation or exceeds the permitted use, you will need to obtain permission directly from the copyright holder. To view a copy of this licence, visit http://creativecommons.org/licenses/by/4. $0 /$.

\section{Appendix}

Table 7 Contact forms self-assessment scales $(N=138)$

\section{Confluent contact form $(\alpha=0.81)$}

Good relationships with others are most important to me

I like to confirm others in what they say

It is important to me to dissolve boundaries and establish closeness

I do not take myself too seriously

When there is harmony with others, I feel good

\section{Intentional contact form $(\alpha=\mathbf{0 . 7 8})$}

I usually have clear goals and ideas

In my assessments of others, I am often right

I often know what someone wants to say before he/she has finished speaking

I can win others over

I can well assess the motives for which other people act

\section{Retroflexive contact form $(\alpha=0.79)$}

I am not so quick to show others what moves me

I am rather reserved

I often suppress my feelings

I am not so quick to approach people

I usually leave initiatives to others

\section{Normative contact form $(\alpha=\mathbf{0 . 8 0})$}

I sometimes find it difficult to let others explain things to me

I often cannot keep to myself and have to improve others when they make mistakes

What others think about me usually does not surprise me

I like to give others tips on how something works or how to do something

It is not easy for me to get involved in uncertain situations
Acknowledgements I would like to take this opportunity to thank the numerous participants in the artop-Institute training programs at the Humboldt-Universität zu Berlin whose participation made this study possible in the first place. I would also like to thank my colleague Matthias Ziegler for critiquing the manuscript.

Funding Open Access funding enabled and organized by Projekt DEAL.

Conflict of interest T. Bachmann declares that he has no competing interests.

\section{References}

Amann, A. (2009). Der Prozess des Diagnostizierens - Wie untersuche ich eine Gruppe? In C. Edding \& K. Schattenhofer (Eds.), Handbuch: Alles über Gruppen.[All about groups] Theorie, Anwendung, Praxis (pp. 404-436). Weinheim: Beltz.

Ancona, D., \& Caldwell, D. (1992). Bridging the boundary: External activity and performance in organizational teams. Administrative Science Quarterly, 37(4), 634-665. https://doi.org/10.2307/ 2393475.

Bachmann, T. (2017). Coaching and group dynamics. In A. Schreyögg \& C. C. Schmidt-Lellek (Eds.), The Professionalization of Coaching (pp. 223-248). Wiesbaden: Springer. https://doi.org/10.1007/ 978-3-658-16805-6_13.

Bachmann, T. (2019a). Gruppenintelligenz - gemeinsam sind wir besser? Gruppe Interaktion Organisation, 50, 397-411. https:// doi.org/10.1007/s11612-019-00490-0.

Bachmann, T. (2019b). Formen des Kontakts [Forms of contact]. Heidelberg: Carl Auer Verlag.

Bachmann, T. (2022). The forms of contact—an approach to theme, process, state, and methods in coaching [in Press]. In S. Greif, H. Moeller, W. Scholl, J. Passmore \& F. Mueller (Eds.), The international handbook of evidence-based coaching-theory, research, and practice. Wiesbaden: Springer Nature.

Bales, R.F. (1950). Interaction process analysis: a method for the study of small groups. Cambridge, MA: Addison-Wesley.

Barry, D. (1991). Managing the bossless team: Lessons in distributed leadership. Organizational Dynamics, 20(1), 31-47. https://doi. org/10.1016/0090-2616(91)90081-J.

Belbin, R. M. (1993). Team roles at work. Oxford: Butterworth-Heinemann.

Benne, K. D., \& Sheats, P. (1948). Functional roles of group members. Journal of Social Issues, 4(2), 41-49. https://doi.org/10.1111/j. 1540-4560.1948.tb01783.x.

Carson, J.B., Tesluk, P.E., \& Marrone, J. A. (2007). Shared leadership in teams: an investigation of antecedent conditions and performance. Academy of Management Journal, 50(5), 1217-1234. https://doi.org/10.5465/amj.2007.20159921.

Caughlin, D.E. (2010). The impact of personality, informal roles, and team informal role configuration on team effectiveness. Doctoral dissertation. Indianapolis: Purdue University.

Costa, P. T., \& McCrae, R.R. (1985). The NEO personality inventory. Odessa, FL: Psychological Assessment Resources.

D’Innocenzo, L., Mathieu, J.E., \& Kukenberger, M. R. (2016). A meta-analysis of different forms of shared leadership-team performance relations. Journal of Management, 42(7), 1964-1991. https://doi.org/10.1177/0149206314525205.

DuBrin, A.J. (1995). The breakthrough team player. New York, NY: American Management Association.

Edmondson, A. C., \& Lei, Z. (2014). Psychological safety: the history, renaissance, and future of an interpersonal construct. Annual Review of Organizational Psychology and Organizational Behavior, 1(1), 23-43. https://doi.org/10.1146/annurev-orgpsych-031413091305. 
Fleeson, W. (2001). Toward a structure- and process-integrated view of personality: traits as density distributions of states. Journal of Personality and Social Psychology, 80(6), 1011-1027. https://doi. org/10.1037/0022-3514.80.6.1011.

Fleeson, W. (2007). Situation-based contingencies underlying traitcontent manifestation in behavior. Journal of Personality, 75(4), 825-862. https://doi.org/10.1111/j.1467-6494.2007.00458.x.

Hale, A. (2009). Moreno's sociometry: Exploring interpersonal connection. Group, 33(4), 347-358.

Hare, A.P. (1976). Handbook of small group research. New York, NY: The Free Press.

Janz, B.D., Colquitt, J.A., \& Noe, R. A. (1997). Knowledge worker team effectiveness: the role of autonomy, interdependence, team development, and contextual support variables. Personnel psychology, 50(4), 877-904. https://doi.org/10.1111/j.1744-6570. 1997.tb01486.x.

Königswieser, R., Wimmer, R., \& Simon, F. B. (2013). Back to the Roots - Die neue Aktualität der (systemischen) Gruppendynamik. Organisationsentwicklung, 1, 65-73.

Kozlowski, S. W., \& Bell, B. S. (2003). Work groups and teams and organizations. In W. C. Borman, D. R. Ilgen \& R. J. Klimoski (Eds.), Handbook of psychology: industrial and organizational psychology (Vol. 12, pp. 333-375). New York, NY: Wiley.

Lewin, K. (1945). The research center for group dynamics at Massachusetts Institute of Technology. Sociometry, 8(2), 126-136. https://doi.org/10.2307/2785233.

Lewin, K. (1951). Field theory in social science: selected theoretical papers (Edited by Dorwin Cartwright). New York, NY: Harpers.

Luhmann, N. (1985). Soziale Systeme [Social systems]. Frankfurt: Suhrkamp.

Mathieu, J. E., Gallagher, P. T., Domingo, M. A., \& Klock, E. A. (2019). Embracing complexity: reviewing the past decade of team effectiveness research. Annual Review of Organizational Psychology and Organizational Behavior, 6, 17-46. https://doi.org/10.1146/ annurev-orgpsych-012218-015106.

McCann, D., \& Margerison, C. (1995). Team management: practical new approaches. Chalford, England: Management Books 2000.

Meyer, H.A., Wrba, H., \& Bachmann, T. (2018). Psychologische Sicherheit: Das Fundament gelingender Arbeit im team. In S. Hess \& H. Fischer (Eds.), Mensch und Computer 2018-Usability Professionals (pp. 189-202). Bonn: Gesellschaft für Informatik e.V. und German UPA e.V.. https://doi.org/10.18420/ muc2018-up-0243.

Moe, N.B., Dingsyr, T., \& Kvangardsnes, O. (2009). Understanding shared leadership in agile development: a case study. 42nd Hawaii International Conference on System Sciences, Big Island. (pp. 1-10). https://doi.org/10.1109/HICSS.2009.480.

Moreno, J. L. (2012). Sociometry, experimental method and the science of society. U.K.: The Northwest Psychodrama Association.

Mumford, T. V., Van Iddekinge, C.H., Morgeson, F.P., \& Campion, M. A. (2008). The team role test: Development and validation of a team role knowledge situational judgment test. Journal of Applied Psychology, 93(2), 250-267. https://doi.org/10.1037/00219010.93.2.250.

Parker, G. M. (1996). Team players and teamwork. San Francisco, CA: Jossey-Bass.

Parsons, T. (1961). An outline of the social system. General introduction II. In T. Parsons, E. Shils, K. D. Naegele \& J. Pitts (Eds.), Theories of society (pp. 30-79). New York, NY: The Free Press.

Perls, F., Hefferline, G., \& Goodman, P. (1962). Gestalt therapy. 4th Edition: New York, NY The Julian Press.

Rapp, T.L., Gilson, L. L., Mathieu, J.E., \& Ruddy, T. (2016). Leading empowered teams: An examination of the role of external team leaders and team coaches. The Leadership Quarterly, 27(1), $109-123$.

Rauthmann, J.F. (2012). You say the party is dull, I say it is lively: a componential approach to how situations are perceived to disentangle perceiver, situation, and perceiver $\times$ situation variance.
Social Psychological and Personality Science, 3(5), 519-528. https://doi.org/10.1177/1948550611427609.

Rauthmann, J.F. (2013). Effects of supplementary and complementary personality-situation fit on personality processes. Psychology of Everyday Activity, 6, 41-63.

Rising, L., \& Janoff, N.S. (2000). The Scrum software development process for small teams. IEEE Software, 17(4), 26-32. https://doi. org/10.1109/52.854065.

Robertson, B.J. (2015). Holacracy: the new management system for a rapidly changing world. New York, NY: Henry Holt and Company.

Schein, E.H., \& Bennis, W. G. (1965). Personal and organizational change through group methods: the laboratory approach. New York, NY: Wiley.

Schermuly, C.C. (2019). New Work und Coaching-psychologisches Empowerment als Chance für Coaches. Organisationsberatung, Supervision, Coaching, 26(2), 173-192.

Schindler, R. (1957). Grundprinzipien der Psychodynamik in der Gruppe. Psyche, 11(5), 308-314.

Schjelderup-Ebbe, T. (1922). Beiträge zur Sozialpsychologie des Haushuhns [Observation on the social psychology of domestic fowls]. Zeitschrift für Psychologie und Physiologie der Sinnesorgane. Abt. 1. Zeitschrift für Psychologie, 88, 225-252.

v. Schlippe, A., \& Schweitzer, J. (2013). Lehrbuch der systemischen Therapie und Beratung I. Goettingen: Vandenhoeck \& Ruprecht.

Stewart, G.L., Fulmer, I.S., \& Barrick, M.R. (2005). An exploration of member roles as a multilevel linking mechanism for individual traits and team outcomes. Personnel Psychology, 58, 343-365.

Tuckman, B.W. (1965). Developmental sequence in small groups. Psychological Bulletin, 63(6), 384-399. https://doi.org/10.1037/ h0022100.

Wheelan, S. A. (2009). Group size, group development, and group productivity. Small Group Research, 40(2), 247-262. https://doi.org/ 10.1177/1046496408328703.

Wheeler, G. (1998). Gestalt reconsidered: a new approach to contact and resistance. Cambridge, MA: The GICPress.

Yalom, I.D. (1995). The theory and practice of group psychotherapy. New York, NY: Basic Books.

Ziegler, M. (2014). Manual Big Five Inventar zur Persönlichkeit in beruflichen Situationen. Wien: Schuhfried.

Ziegler, M., Bensch, D., Maaß, U., Schult, V., Vogel, M., \& Bühner, M. (2014). Big five facets as predictor of job training performance: the role of specific job demands. Learning and Individual Differences, 29, 1-7. https://doi.org/10.1016/j.lindif.2013.10.008. 


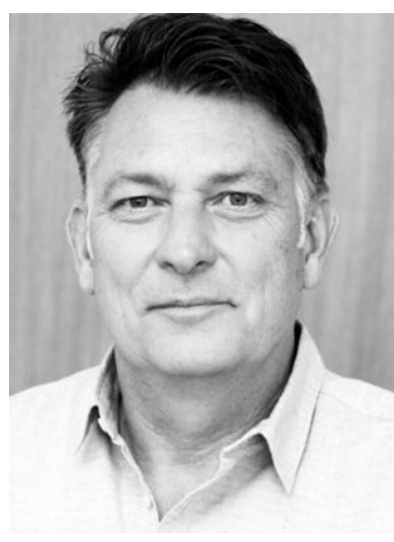

Dipl.-Psych., PD Dr. rer. nat Thomas Bachmann born in 1964, is co-founder and partner at artop $\mathrm{GmbH}$, the renowned consulting, training, and research institute at the Humboldt University of Berlin in the field of personnel and organisational development and usability. Since 1993, he has worked as a consultant and coach for organisations, management executives, and teams. He completed his psychology degree in 1994, majoring in industrial and organisational psychology, clinical psychology, and informatics. Thomas Bachmann is a communications trainer, organisational consultant, coach and Gestalt therapist. Since 2004 he has been a senior coach of the German Federal Association of Executive Coaching (DBVC) and since 2018 a Professional Certified Coach (PCC) of the International Coach federation (ICF). He also a lecturer and researcher at the Humboldt-University of Berlin. His research interests are teamwork, group dynamics, shared leadership, psychological safety, and the professionalization of coaching. Since 2001, he has worked as an instructor and teaching trainer for coaches and consultants. 